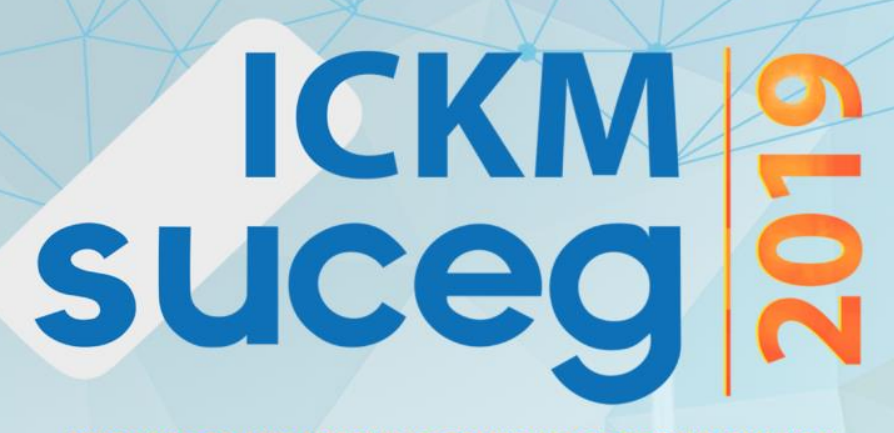

\title{
A GESTÃO DO CONHECIMENTO COMO AUXÍLIO À INTELIGÊNCIA DE SEGURANÇA PÚBLICA
}

Felipe Pereira de Melo

Mestrando do Programa de Pós-Graduação em Gestão do Conhecimento nas Organizações do Centro Universitário de Maringá - UNICESUMAR. felipedemelo.esc@ gmail.com

Arthur Gualberto da Cruz Bacelar Urpia

Orientador. Vice-coordenador do Programa de Pós-Graduação em Gestão do Conhecimento nas Organizações da UNICESUMAR. arthur.urpia@unicesumar.edu.br

Rejane Sartori

Orientadora. Docente do Programa de Pós-Graduação em Gestão do Conhecimento nas Organizações da UNICESUMAR. Pesquisadora do ICETI. rejane.sartori@unicesumar.edu.br

\section{RESUMO}

Objetivo: O presente estudo tem como objetivo trazer uma contribuição acerca da discussão sobre o compartilhamento de conhecimentos na atividade de Inteligência de Segurança Pública (ISP), visto sua importância na produção de conhecimentos úteis, oportunos e assessoráveis ao processo decisório, seja nos níveis tático, estratégico ou operacional.

Design/Metodologia/Abordagem: Este trabalho se configura como exploratório, com abordagem qualitativa.

Resultados: Como principais resultados, observa-se que o compartilhamento de conhecimentos no âmbito das Instituições de Segurança Pública, a partir da Gestão do Conhecimento, possibilita uma constante integração entre as unidades de inteligência, facilita o processo de inovação e 
desenvolvimento, bem como amplia as perspectivas para a melhor tomada de decisões, proporcionando maior eficiência e eficácia em matéria organizacional.

Originalidade/valor: $O$ tema é de exponencial relevância visto a carência de produções acadêmicas com a perspectiva de compartilhamento de conhecimentos na atividade de ISP.

Palavras-chave: Gestão do Conhecimento; Compartilhamento do Conhecimento; Inteligência de Segurança Pública; Inteligência Policial; Contrainteligência. 


\title{
KNOWLEDGE MANAGEMENT AS AID TO PUBLIC SECURITY INTELLIGENCE
}

\begin{abstract}
Goal: This study aims to contribute to the discussion about knowledge sharing in the Public Security Intelligence (PSI) activity, considering its importance in the production of useful, timely and advisable knowledge to the decision-making process, whether tactical, strategic. or operational. Design / Methodology / Approach: This work is configured as exploratory, with a qualitative approach.

Results: As main results, it is observed that knowledge sharing within Public Security Institutions, through Knowledge Management, enables a constant integration between intelligence units, facilitates the process of innovation and development, as well as broadens perspectives. for better decision making, providing greater efficiency and effectiveness in organizational matters.

Originality / value: The theme is of exponential relevance given the lack of academic productions with the perspective of knowledge sharing in the PSI activity.
\end{abstract}

Keywords: Knowledge Management; Knowledge Sharing; Public Security Intelligence; Police intelligence; Counterintelligence. 


\section{INTRODUÇÃOO}

No atual cenário político e social é perceptível o crescente aumento nos índices de violência de todo o Brasil, conforme dados publicados pelo Atlas da Violência em 2018 (Cerqueira et al., 2018), despertando assim a necessidade de repensar a Gestão Estratégica em matéria de segurança pública. Assim, visando aperfeiçoar as ações de segurança pública, os órgãos de Inteligência de Segurança Pública (ISP) procuram, por meio de suas atividades, estar à frente das organizações criminosas, promovendo operações sistemáticas e exploratórias e permitindo aos decisores acesso aos conhecimentos assessoráveis, seja no apoio tático, estratégico ou operacional.

De modo geral, a segurança pública está relacionada à prestação de serviços públicos, efetuada por instituições desse setor, a fim de manter a paz social, garantir a proteção dos direitos individuais e assegurar o pleno exercício da cidadania. Neste sentido, o Subsistema de Inteligência de Segurança Pública (SISP) tem como missão coordenar e integrar as atividades de ISP em todo País, visando suprir com informações para a melhor tomada de decisões (Decreto $N^{\circ} 3695,2000$ ).

A ISP é conceituada como o exercício permanente e sistemático de ações especializadas a fim de que se possa identificar, avaliar e acompanhar as ameaças de qualquer natureza, reais ou potenciais, no âmbito da segurança pública (Brasil, 2007, apud Moreira; Ferro, 2017). Kent (1967) considera que a atividade de Inteligência pode ser caracterizada como produto, atividade e organização. Como produto trata-se do conhecimento obtido por meio da análise de dados e informações; como atividade refere-se ao meio pelo qual as instituições utilizam-se da metodologia de produção de conhecimentos para desenvolver produtos que possam subsidiar as tomadas de decisão no âmbito estratégico, tático e operacional (Melo, 2017); e como organização diz respeito à Inteligência em âmbito institucional, com suas características singulares. Um dos pontos que merece destaque é que, em âmbito organizacional, a Inteligência dispõe, além de informações disponíveis, de acesso a dados e informações protegidas ou negadas (Ferreira, 2017).

Tendo em vista que a atividade de Inteligência é um processo de integração entre os diferentes órgãos e que os dados, informações e conhecimentos são as suas matérias primas, temse que a Gestão do Conhecimento (GC) pode contribuir de forma significativa para a melhoria dos processos no âmbito organizacional. Como afirma Freire (2018) no âmbito da atividade de ISP a GC tem o propósito aprimorar a comunicação entre pessoas, processos e serviços. 
Desse modo, o presente estudo tem como objetivo trazer uma contribuição acerca da discussão sobre o compartilhamento de conhecimentos na atividade de ISP. Em consulta preliminar efetuada nas bases de dados Scielo, Web of Science e Coordenação de Aperfeiçoamento de Pessoal de Nível Superior (CAPES), percebe-se que os trabalhos que discutem sobre GC na Segurança Pública não dão a devida atenção para o compartilhamento de conhecimentos. Diante disso, o aporte deste trabalho é dar luz a esta discussão no âmbito da atividade de ISP. Para tal, do ponto de vista metodológico, este trabalho configura-se como exploratório, com abordagem qualitativa.

\section{A GESTÃO DO CONHECIMENTO}

Historicamente, o conhecimento foi essencial para a sobrevivência e manutenção das organizações durante duas das maiores crises econômicas existentes na história, a crise do petróleo na década de 70 e a crise dos subprimes em meados de 2007. Evidente que não se adota uma noção de causa e efeito e que há sempre inúmeros fatores interligados aos eventos, mas sem dúvida estes são fatores de grande relevância visto que, devido à escassez de recursos, foi necessário que as empresas se adaptassem ao cenário econômico, político e social.

Além disso, toda a proteção do conhecimento empresarial, que era característica do passado, acabou se tornando obsoleta. “[...] De modo geral, porém, é virtualmente impossível impedir os concorrentes de copiar e até mesmo aperfeiçoar produtos e métodos de produção com razoável rapidez numa era caracterizada pela mobilidade [...]” (Davenport; Prusak, 1999, p. 19). Neste sentido, esses autores descreveram que o conhecimento pode propiciar uma vantagem competitiva sustentável, sendo que as organizações, para se manterem ativas e competitivas no cenário global, necessitam utilizar-se do conhecimento existente e assim produzir inovações capazes de mantê-las em constante atualização, em um ciclo ilimitado de crescimento.

A doutrina em GC tem mostrado que a vantagem competitiva está diretamente ligada à inovação e revela ainda que esta é gerada por meio do conhecimento existente na própria organização, pela transformação do conhecimento tácito em conhecimento explícito (Nonaka; Takeuchi, 1997). Embora não exista consenso sobre o conceito de GC, visto que se modifica conforme as perspectivas, características e objetivos a que se propõe, Alavi e Leidner (2001, p. 131) mencionam que é uma área que “envolve diferentes etapas, interdependentes e relacionadas à 
criação, captura, armazenamento e compartilhamento do conhecimento, sendo um fenômeno contínuo, complexo e dinâmico".

Para Bukowitz e Williams (2002, p.17), a GC consiste no "processo pelo qual a organização gera riqueza, a partir do seu conhecimento ou capital intelectual”. Argumentam ainda esses autores que a GC "fornece uma nova lente, através da qual a organização e o próprio processo de gestão podem ser vistos. Ela traz para o foco diferentes aspectos da organização, que, por sua vez, terão impacto tanto no que é gerenciado quanto em como isso é feito" (Bukowitz; Williams, 2002, p. 367). Na visão de Probst, Raub e Romhardt (2002), são métodos para influenciar os ativos intelectuais da organização e orientar seu desenvolvimento.

Evidente que quando se trata de prestação de serviços públicos a perspectiva de gerar valor muda. Conforme afirma Batista (2006, p.18), "enquanto o setor privado implementa a GC visando o lucro e o crescimento, a administração pública busca principalmente qualidade, eficiência, efetividade social e desenvolvimento econômico e social". Neste sentido, avalia-se que enquanto nas organizações privadas a GC está ligada a competitividade, manutenção e sobrevivência organizacional, no serviço público procura tornar a referida organização efetiva e eficaz, promovendo relevante impacto social na perspectiva de auxiliar na gestão de pessoas, processos e tecnologias nas organizações públicas.

Davenport e Prusak (1999) consideram que o compartilhamento de conhecimentos é considerado por muitos autores como um dos aspectos que mais contribuem para o desenvolvimento organizacional. Transferência, disseminação, transmissão, difusão, compartilhamento e troca são termos, por vezes, tratados pela doutrina como sinônimos, seja do individual para o coletivo, organizacional e entre organizações (Osinski; Roman; Selig, 2015).

O compartilhamento de conhecimentos pode ser identificado como um dos principais focos da GC, visto que esse processo promove a ligação entre o conhecimento individual (tácito) e o conhecimento coletivo ou organizacional (Hendriks, 1999). Quando os conhecimentos são compartilhados otimizam-se os recursos uma vez que o compartilhamento daquilo que já se tem dominado poupa os dispêndios da organização (Tonet; Paz, 2006), favorecendo, assim, que se concentre nas necessidades que ainda carecem de atenção. Além disso, o compartilhar vai muito além de apenas fornecer conhecimentos, pois promove a criação de novos conhecimentos, favorece a socialização e o desenvolvimento organizacional, uma vez que a capacidade de produzir 
conhecimentos, a partir do compartilhamento, facilita o processo de aprendizagem e aperfeiçoa a capacidade estratégica, atingindo melhores resultados (Freire; Furlan; Silveira, 2018).

Entretanto, no que diz respeito ao compartilhamento de conhecimentos, faz-se importante destacar que este tema ainda é pouco trabalhado entre organizações diferentes, sendo mais abundante os trabalhos que o discutem dentro da própria organização. Isto se dá devido a uma perspectiva competitiva entre as organizações privadas, em que o conhecimento, como maior ativo, permite que uma organização se destaque perante outras. Todavia, no serviço público, não há, ou melhor, não deveria existir, a concorrência entre organizações públicas, visto que seu objetivo é fornecer a melhor prestação de serviços à população. Neste sentido, é necessário realizar um esforço para compreender como seria possível o compartilhamento de conhecimentos entre órgãos públicos diante dos benefícios que pode trazer para a sociedade.

Assim sendo, um dos modelos que pode ser utilizado com o intuito de verificar como pode ocorrer o compartilhamento de conhecimentos entre órgãos públicos é o proposto por Tonet e Paz (2006), composto de quatro etapas integradas: I) iniciação, que consiste em ações voltadas para identificar os conhecimentos necessários, as oportunidades para empregar os novos conhecimentos e as fontes para obtê-los; II) implementação, que se refere a ações para integrar fontes e destinatários do conhecimento; III) apoio, que se caracteriza por ações que visam promover o compartilhamento, seja por meio de oportunidades ou orientação prática; e IV) incorporação, em que o conhecimento compartilhado é disseminado e aplicado na prática.

Desta forma, pode-se considerar que o compartilhamento de conhecimentos promove a integração e a confiança entre as instituiçõos, facilita o processo de resolução para soluções emergentes, bem como permite que os recursos, por vezes escassos, sejam melhor aplicados, propiciando o desenvolvimento inovativo no meio organizacional. Ademais, verifica-se que sua aplicação é viável inclusive entre diferentes órgãos públicos.

\section{INTELIGÊNCIA DE SEGURANÇA PÚBLICA}

A ISP tem sido pauta de inúmeras plataformas eleitorais, sendo perceptível, em discursos inflamados, que o fundamental é desenvolver e investir na ISP, sendo ela o remédio para todas as enfermidades. Na prática, é latente que os investimentos para a ISP e para as Polícias Investigativas de todo o Brasil permanecem por vezes no esquecimento, os quais geralmente são voltados a uma 
política de ostentação, cativando a opinião pública, com o escopo de que isto gera maior "sensação de segurança", ou seja, mero paliativo para os reais problemas enfrentados.

A atividade de Inteligência no Brasil tem início em 1927 durante o então Governo de Washington Luís, com a criação do Conselho de Defesa Nacional, cuja proposta era exercer a atividade de Inteligência de Estado, visando proteger o Brasil de possíveis ameaças (ABIN, 2015). Todavia, a noção de Inteligência e Contrainteligência de fato são instituídas em 06 de setembro de 1946, durante o Governo de Eurico Gaspar Dutra, com a criação do Serviço Federal de Informações e Contrainformações (SFICI) (ABIN, 2015).

A Lei $n^{\circ}$ 9.883, de 7 de dezembro de 1999, instituiu o Sistema Brasileiro de Inteligência (SISBIN) e criou a Agência Brasileira de Inteligência (ABIN). Essa Lei foi regulamentada pelo Decreto $\mathrm{n}^{\circ} 4.376$, de 13 de setembro de 2002, que dispõe sobre a organização e o funcionamento do SISBIN e considera Inteligência como a atividade que objetiva prevenir, detectar, obstruir e neutralizar a inteligência adversa e ações de qualquer natureza que constituam ameaça à salvaguarda de dados, informações e conhecimentos de interesse da sociedade e do Estado, bem como das áreas e dos meios que os retenham ou que transitem.

Assim sendo, embora o SISBIN tivesse sido criado com uma proposta mais voltada à Inteligência de Estado, necessitava-se da criação de um organismo voltado à ISP. Quando se trata da atividade de ISP, deve-se ter claro que esta surge diante das necessidades em mover o aparelho estatal para prevenir e estar à frente das práticas criminosas no Brasil. Nesse sentido, o Decreto $\mathbf{n}^{\mathbf{o}}$ 3.695, de 21 de dezembro de 2000, cria o Subsistema de ISP no âmbito do SISBIN, tendo como órgão central a Secretaria Nacional de Segurança Pública (SENASP), vinculada ao Ministério da Justiça.

Conforme afirma Kent (1967), a Inteligência pode ser caracterizada como produto, atividade e organização. Desse modo, como produto está relacionada ao conhecimento obtido por meio da análise de dados e informações; como atividade diz respeito ao meio pelo qual as instituições utilizam-se da metodologia de produção de conhecimentos para desenvolver produtos que possam subsidiar as tomadas de decisão no âmbito estratégico, tático e operacional (Melo, 2017); e como organização trata-se da Inteligência em âmbito institucional, com suas características singulares. Um dos pontos que merece destaque é que, em âmbito organizacional, a 
Inteligência dispõe, além de informações acessíveis, o acesso a dados e informações protegidas ou negadas (Ferreira, 2017).

Segundo a Doutrina Nacional de Inteligência de Segurança Pública (DNISP), a ISP é conceituada da seguinte forma:

[...] o exercício permanente e sistemático de ações especializadas para identificar, avaliar e acompanhar ameaças reais ou potenciais na esfera de segurança pública, basicamente orientadas para produção e salvaguarda de conhecimentos necessários para subsidiar os governos - tanto em nível federal como estadual - , à tomada de decisões e a elaboração de políticas de planos de segurança pública (Brasil, 2007, s/p apud Moreira; Ferro, 2017, p. 61).

Já a Inteligência Policial é conceituada por Ferro Júnior (2008, p.52) como a "atividade que objetiva a obtenção, análise, produção e disseminação de informações e conhecimentos sobre fatos e situações de imediata ou potencial influência na criminalidade na Segurança Pública [...]”. No que diz respeito aos ramos de atuação, a inteligência policial pode ser dividida em Inteligência e Contrainteligência, sendo esta, conforme a Doutrina supramencionada, definida como

o ramo da atividade de Inteligência de Segurança Pública que se destina a produzir conhecimentos para proteger a atividade de Inteligência e a instituição a que pertence, de modo a salvaguardar dados e conhecimentos sigilosos e identificar e neutralizar ações adversas de qualquer natureza. A Contrainteligência assessora também em assuntos internos de desvios de conduta, relacionadas à área de segurança pública. (DNISP, 2009, apud Siqueira, 2009, p.225).

Desta forma, quando se fala em Inteligência, esta pode ser pensada em uma perspectiva macro como sistema, como ramo e como produto gerado por parte de seus analistas. Com relação ao ramo de Inteligência, este pode ser considerado em suas duas divisões básicas, Análise e Operações. O setor de Análise é aquele por meio do qual se produz informações e conhecimentos de inteligência no âmbito da organização e o setor de Operações é responsável por buscar dados e informações protegidos ou negados (Melo, 2017).

\section{CONTRAINTELIGÊNCIA DE SEGURANÇA PÚBLICA}

A Contrainteligência, conforme a Doutrina Nacional de Inteligência de Segurança Pública, é definida como o ramo destinado a produzir conhecimentos para preservar a atividade de 
Inteligência e a instituição a que pertence, protegendo e neutralizando ações adversas de qualquer natureza (DNISP, 2009, apud Siqueira, 2009).

De forma geral, pode-se afirmar que praticamente todas as instituições de Segurança Pública do País têm a noção de que o desenvolvimento estratégico, tático, administrativo e operacional é imprescindível para o enfrentamento à criminalidade. Conforme ilustrado por Cepik (2003, p.57), ao tratar dessa temática "a principal missão da Contrainteligência é garantir que os 'outros' só conheçam o que quisermos que eles conheçam sobre nós mesmos". Desta forma, a Contrainteligência tem papel fundamental no desenvolvimento da efetividade em matéria de proteção institucional, devendo ter sua aplicabilidade irrestrita a meras conjecturas idealistas, visto que no atual cenário político-social é perceptível uma constante evolução por parte das organizações criminosas.

\begin{abstract}
O país necessita, urgentemente, de especialista em Inteligência Estratégica de Segurança Pública. Analistas que dominem as técnicas e métodos da análise prospectiva e da análise de riscos. Que saibam abordar e estudar os crimes e os criminosos a partir de novos paradigmas, dando-lhes um enfoque global. Analistas que sejam verdadeiramente capazes de definir e apontar correlações entre os diversos fatores de influência relacionados ao surgimento e a evolução dos fenômenos criminais. Profissionais de inteligência com a condição efetiva de entregar aos níveis político e estratégico conhecimentos sistemáticos que lhes permitam visualizar, no presente, a multiplicidade e os graus de incerteza dos futuros possíveis, para que estas autoridades possam, a partir de então, definir as melhores estratégias de segurança pública com o objetivo de evitar as surpresas estratégicas e obter superioridade e surpresa estratégica frente aos fenômenos criminais modernos (Rockembach, 2017, p. 325).
\end{abstract}

É notório também que a criminalidade tem se adaptado ao contexto, especialmente no tocante à elaboração de estratégias e desenvolvimento de ações por parte das organizações criminosas, a fim de potencializar seus resultados, diminuir suas perdas e estender seus domínios, levando à constante deturpação da tranquilidade pública, ao abalo das forças de segurança e até mesmo à criação de Estados paralelos que, de forma constante, se embatem em "Guerrilha Urbana".

A dinâmica social e o aumento da criminalidade obrigaram as instituições de segurança pública a desenvolverem mecanismos de defesa interna e externa. Um dos fatores que motivou essa política foi à profissionalização e organização da criminalidade, onde grupos organizados passaram a ingressar criminosos nas fileiras das instituições de segurança pública, com a finalidade de obtenção de informações privilegiadas e de corromper os demais integrantes da instituição (Siqueira, 2009, p. 225). 
A despeito do fato de que a Contrainteligência é imprescindível para as ISP, ainda predomina um enorme abismo entre a teoria e prática. Dentre os segmentos de Contrainteligência, esta pode ser dividida em Segurança Orgânica, Segurança Ativa e Segurança de Assuntos Internos. A Segurança Orgânica compõe um conjunto de medidas passivas, de caráter meramente defensivas, destinadas a proteger as instituições das diversas ameaças que possam surgir. Trata-se do conjunto de ações protetivas integradas, destinadas a proteger os recursos humanos, a documentação, as instalações, o material, as comunicações, a telemática, informática e as operações, visando à efetiva proteção diante de qualquer natureza adversa. Dentre os ramos de Segurança Orgânica pode-se destacar a segurança de pessoal, segurança de documentação e material, segurança das telecomunicações, telemática e informática e segurança das áreas e instalações (Curso de Introdução à Atividade de Inteligência [CIAI], 2015).

Para que se consiga desenvolver a Segurança Orgânica, a instituição deve possuir um Plano de Segurança Orgânica oriundo de um trabalho de Análise de Riscos, o qual estabelece responsabilidades, identifica os recursos disponíveis e determina as ações a serem tomadas quando necessário. A elaboração da Análise de Riscos deve seguir metodologia própria com base no estudo da situação, decisão, elaboração do plano, implementação e supervisão das ações planejadas (CIAI, 2015). O produto gerado servirá de elementos para que possam ser estabelecidos protocolos de atuação diante das necessidades elencadas.

Por sua vez, entende-se por Segurança Ativa o conjunto de medidas protetivas, ofensivas, destinadas a detectar, identificar, avaliar, analisar e neutralizar as ações adversas de elementos ou grupos de qualquer natureza, que atentem contra a Segurança Pública (DNISP, 2009). Dentre estas medidas estão contrapropaganda, contraespionagem, contra sabotagem e contraterrorismo.

Por fim, a Segurança de Assuntos Internos é o conjunto de medidas destinadas à produção de conhecimentos que visam assessorar as ações de correição das instituições públicas. São ações destinadas apenas à "assessoria" das Corregedorias, não exercendo necessariamente seu papel. Essas ações tendem a oferecer suporte no tocante às informações referentes aos recursos humanos da instituição, bem como atuar na proteção da imagem institucional, exercendo importante papel (CIAI, 2015). 
Como já mencionado, a Contrainteligência tem importância fundamental na proteção dos dados, informações e conhecimentos, e nesse contexto tem-se o Conhecimento Sensível, que se refere a todo conhecimento considerado sigiloso ou estratégico, cujo acesso não autorizado pode comprometer a consecução dos objetivos nacionais e resultar em prejuízos ao país, necessitando de medidas especiais de proteção (Portaria nº 42 GSIPR, 2009).

A atividade de Inteligência está relacionada a uma verdadeira troca de informações constantes em prol de um objetivo maior, que é a Segurança Pública. Além disso, para a efetiva ação de Contrainteligência, as ações individuais e coletivas devem ser pautadas em cautelas e zelos constantes (Brasil, 2004). Hamada (2017, p.31) considera que:

(...) há a necessidade de que haja o entendimento por parte dos diversos atores de que o conhecimento empírico não é a única base para o exercício da atividade de inteligência, mas sim a busca pelo seu equilíbrio com o aperfeiçoamento da teoria, seja pelo desenvolvimento de novos conceitos, seja pela reflexão dos processos existentes.

Nesse contexto Rockembach (2017, p. 323) ilustra afirmando que "desenvolver a mentalidade de inteligência nos altos gestores da segurança pública passa a ser, portanto, outro dos desafios da ISP para os próximos anos". Ou seja, esta concepção deve estar principalmente atrelada aos decisores, o que facilitará o engajamento e a mudança de paradigmas.

Frisa-se que de nada adianta o conhecimento ser despejado e não praticado. Cada um dos segmentos de Contrainteligência deve estar enraizado na matriz do indivíduo e evidenciado em seu cotidiano. Muito além da proteção ao conhecimento sensível, esta Cultura de Inteligência deve permitir que o profissional de segurança pública utilize das medidas de Contrainteligência no dia a dia, seja em seu deslocamento, nas suas relações sociais etc., propiciando, assim, que não se torne alvo e vítima da criminalidade.

Na fase de sensibilização o objetivo é fazer com que os gestores tomem conhecimento da existência da atividade de inteligência. $\mathrm{Na}$ fase de conscientização a missão consiste em fazer com que os tomadores de decisão, além de conhecer, passem a acreditar na importância, eficiência e eficácia da Inteligência na solução de problemas relacionados à segurança pública. Na fase de capacitação a meta é fazer com que as autoridades não só conheçam os métodos, técnicas e práticas da atividade de inteligência, mas que também comecem a fazer uso delas no dia a dia normal de trabalho. Sem a mentalidade de inteligência o Processo Decisório jamais saberá usar a Inteligência de forma eficiente e eficaz (Rockembach, 2017, p. 324). 
Obviamente, o produto da ISP e da investigação criminal são diferentes, pois enquanto a ISP trata do processamento e da análise de dados, resultando na produção de "conhecimentos" que servirão de suporte para um Decisor, na investigação criminal o objetivo final é a obtenção de elementos probatórios. Resta claro que desde 2014, com a criação do Relatório Técnico na Doutrina Nacional de Inteligência de Segurança Pública (DNISP), as Agências de Inteligência podem contribuir efetivamente no auxílio técnico (Ferreira, 2017).

Os Serviços de Inteligência podem servir como meio auxiliar no tocante à investigação criminal, podendo ou não ser utilizadas no conjunto probatório, todavia, comprometidos com o mesmo objetivo, qual seja, a redução e o combate à criminalidade (Melo, 2017, p. $68)$.

Outro ponto que merece destaque é o fato da integração de informações com outras instituições, pois um dos maiores problemas vividos, pelas mais diversas entidades do mundo, é considerar que a informação tem dono, sendo que, ao não compartilhá-la, fragilizam-se as estruturas existentes e se estabelece um clima de desconfiança perene entre as Agências (Brasil, 2004). Sendo assim, uma Cultura de Inteligência entre os mais diversos setores das instituições de segurança pública é indispensável para o seu pleno desenvolvimento, visto que, sem ela, a preocupação com a proteção à informação sensível e aos seus recursos humanos e materiais estarão completamente à deriva, fragilizando-a como um todo. Certamente, sem uma base sólida de formação e acompanhamento dificilmente se conseguirá traçar estratégias para o desenvolvimento institucional e para o enfrentamento da criminalidade organizada, que mantém um constante aperfeiçoamento de suas ações ilícitas.

\section{GESTÃO DO CONHECIMENTO NA SEGURANÇA PÚBLICA}

A Segurança Pública, de modo geral, corresponde à prestação de serviços públicos, por parte de suas instituições, a fim de manter a paz social, bem como garantir a proteção dos direitos individuais e assegurar o pleno exercício da cidadania. Conforme contido no artigo $1^{\circ}$ do Decreto

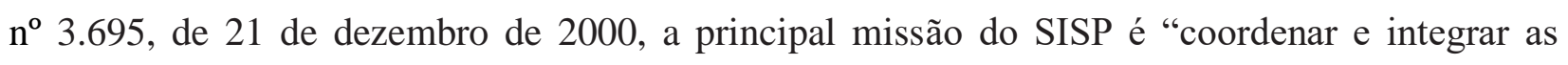
atividades de inteligência de segurança pública em todo País e suprir os governos federal e estadual de informações que subsidiem a tomada de decisões nesse campo" (Decreto n 3.695, 2000). 
Para Ferro Júnior (2008), o binômio tecnologia e inteligência representa elemento fundamental para toda a organização policial em um contexto de enorme complexidade social, e na atualidade, conhecida como "era da informação", é imprescindível um constante processo evolutivo da organização policial, visto que a criminalidade atua, sobretudo, na turbulência social, em que fatores como velocidade, conectividade e intangibilidade e inovação caracterizam a complexidade do mundo contemporâneo. Esse autor considera que

\begin{abstract}
os organismos de Segurança Pública têm imenso repositório de informações, entretanto, ainda não se consegue desenvolver um ciclo de gestão para o uso efetivo de conhecimento existente. $\mathrm{Na}$ verdade, apesar dos esforços, a cultura presente nas organizações está na compartimentação e concentração de informações. A informação está disponível em algum lugar, contudo não é possível acessá-la. São consideráveis as estruturas com eficiência potencial (aquela estruturada em computadores), porém a eficiência real somente é alcançada com a integração e com adição do capital humano, o conhecimento que está na cabeça dos policiais (Ferro Júnior, 2008, p. 287).
\end{abstract}

Neste sentido, ao se tratar da GC no âmbito da Segurança Pública, Freire (2018, p.7) considera que "a Gestão do Conhecimento na atividade de Inteligência de Segurança Pública tem o objetivo de melhorar a comunicação entre pessoas, processos e serviços, fomentando a socialização, o registro, o fluxo e a aplicação do conhecimento de modo eficaz". Partindo para uma perspectiva macro, o modelo engessado das instituições policiais, ainda enraizado em uma postura conservadora, entra em conflito com as novas dinâmicas sociais, necessitando que sua concepção base seja reestruturada para um modelo mais flexível. Morgan (1996, p. 82) discute que "sob circunstâncias que mudam, é importante que os elementos da organização sejam capazes de questionar a propriedade daquilo que estão fazendo e modifiquem sua ação para levar em conta novas situações", ou seja, esta "plasticidade organizacional"1 torna-se imperativo para a gestão das organizações no atual contexto global.

Tendo em vista que a matéria prima da ISP e da GC são dados, informações e conhecimentos, torna-se fundamental discutir suas singularidades. Do ponto de vista da GC, os dados são caracteres distintos e objetivos relativos, ou seja, são registros estruturados dentro da

${ }^{1}$ Plasticidade organizacional trata-se de expressão que procura incorporar o sentido de a organização moldar-se conforme as necessidades emergentes. 
organização. São descrições parciais sem significados inerentes, não fornecendo julgamentos ou interpretações. Já informação, como sua própria nomenclatura diz, diz respeito a "informar", ou seja, ela muda o modo como o destinatário interpreta algo, exercendo impacto sobre seu julgamento. Desta forma, a informação tem propósito definido e relevância característica (Davenport; Prusak, 1999).

Com relação ao conhecimento, este pode ser entendido como o produto dotado de valor, com característica intangível; possui relevância significativa para os rumos da organização, influenciando diretamente nas tomadas de decisão e na geração de inovações. Embora dotado de enorme complexidade, o conceito de conhecimento contempla alguns componentes básicos, tais como a experiência, a verdade, o discernimento e as normas práticas (Davenport; Prusak, 1999).

Desta forma, a GC pode contribuir de forma significativa para o desenvolvimento das instituições de Inteligência. Sem dúvida, um dos principais desafios é como compartilhar informações e conhecimentos de inteligência. Muitos dos produtos, ou seja, documentos produzidos no âmbito da inteligência, são classificados à luz do que estabelece a Lei de Acesso à Informação (Lei n ${ }^{\circ}$ 12.527/2011) e desse modo, uma das formas de lidar com esta dificuldade está na necessidade de conhecer e estabelecer termos de confidencialidade entre os Agentes da própria organização. Por exemplo, se a Agência “A” possui necessidade de conhecer determinado assunto, pois a informação e o conhecimento podem trazer impacto a esta, cabe à Agência "B" suprir com todo o repertório necessário para auxílio, diminuindo custos, despendimento de recursos humanos e tecnológicos.

O compartilhamento de conhecimentos em meio aos órgãos de ISP segue como sendo a última etapa do Ciclo de Produção de Conhecimentos (CPC), no qual é composto por planejamento, reunião de dados, processamento e difusão. Como forma de facilitar o processo de difusão, tem-se que o modelo de compartilhamento do conhecimento proposto por Tonet e Paz (2006) pode ser adaptado para o compartilhamento de conhecimentos entre órgãos de ISP, sendo sugerido que nas fases de iniciação os analistas identifiquem as necessidades de se conhecer, como geralmente já ocorre na prática em grande parte dos órgãos de ISP; na de implementação institucionalize-se a proposta de integração por parte dos próprios órgãos de ISP, bem como da Secretaria de Segurança Pública, estabelecendo os regulamentos para sua implantação; na de apoio, sugere-se ações de compartilhamento de conhecimento, tais como: 
(a) Eventos de conhecimentos genéricos: como medida proativa dos órgãos de ISP, o envio sistemático de documentos que possam ser úteis para as respectivas unidades de inteligência, bem como as suas organizações; reuniões periódicas para a discussão de implementos inovativos;

(b) Eventos de conhecimentos específicos: reuniões entre os decisores dos respectivos órgãos de ISP, bem como utilização de aplicativos com criptografia para o compartilhamento de conhecimentos, conforme a necessidade e urgência na tomada de decisões;

(c) Eventos com especialistas de conhecimentos: integração entre os recursos humanos dos diferentes órgãos de ISP, a fim de que se promova, por meio de seminários, congressos, eventos e reuniões, o compartilhamento de conhecimentos específicos; e

(d) Eventos de networking: realização de eventos como congressos, reuniões, seminários etc., a fim de que haja integração entre os recursos humanos dos diferentes órgãos de ISP ou com demais instituições de interesse.

Por fim, na fase de incorporação, que ocorra a aplicação do conhecimento compartilhado na prática como instrumento de auxílio ao processo de tomada de decisões.

\section{CONSIDERAÇÕES FINAIS}

O compartilhamento do conhecimento é um importante processo da GC e sua prática deve ser incentivada nas organizações, visto que, na atualidade, a vantagem competitiva está diretamente ligada à inovação e esta, por sua vez, é gerada por meio do conhecimento existente na própria organização, ou seja, por meio da transformação do conhecimento tácito em explícito. Embora seja pacífico o entendimento de que a ISP no Brasil está muito aquém de ter todo seu potencial desenvolvido, é notável o comprometimento das instituições em desenvolver ferramentas e mecanismos de forma constante, visando a eficácia no combate à criminalidade, seja de forma sistemática ou exploratória.

Diante disso, o objetivo geral deste trabalho consistiu em trazer uma contribuição acerca da discussão sobre o compartilhamento de conhecimentos na atividade de ISP. Com isto, inicialmente, verificou-se ser indiscutível que, para se obter efetividade em matéria de segurança pública, faz-se 
necessário o desenvolvimento do compartilhamento de conhecimentos em meio às instituições e seus recursos humanos, advinda de uma formação inicial e contínua, enraizada na matriz do indivíduo e evidenciada em seu cotidiano. Ainda, este compartilhamento, como forma de cultura organizacional, permite que ocorra o fluxo constante de interação entre seus recursos humanos, possibilitando que o conhecimento seja de fato considerado o maior ativo intangível nas organizações de segurança pública.

Desta forma, a atividade de Inteligência, ao produzir conhecimentos assessoráveis, permite o desenvolvimento de medidas proativas a fim de melhorar a eficiência em segurança pública, avaliando os cenários e as variáveis de forma ampla. Assim, a implementação da prática do compartilhamento de conhecimentos no âmbito das instituições de ISP pode propiciar uma constante integração organizacional, permitindo, com isto, que as atuações não sejam refeitas a todo instante, mas que haja uma melhor utilização dos recursos existentes e de adaptação conforme as necessidades. Ademais, ao compartilhar conhecimentos, os Agentes devem entender que estão contribuindo para o desenvolvimento de inovações e para o sistema como um todo, propiciando maior eficiência e eficácia organizacional. Desse modo, essa prática permite que os recursos humanos existentes aumentem suas potencialidades em um fluxo de constante troca e desenvolvimento.

Assim sendo, o compartilhamento de conhecimentos no âmbito das instituições de ISP, a partir da GC, propicia uma constante integração entre as unidades de Inteligência, facilita o processo de inovação e desenvolvimento, bem como amplia as perspectivas para a melhor tomada de decisões, proporcionando maior eficiência e eficácia em matéria organizacional.

Por fim, como um importante resultado deste trabalho, foi proposto que, para que haja um efetivo compartilhamento de conhecimentos entre os órgãos de ISP, estes podem adaptar as seguintes fases do modelo de compartilhamento de conhecimentos, de autoria de Tonet e Paz (2006), a saber: iniciação, implementação, apoio e incorporação.

Como desdobramentos futuros deste estudo verifica-se a necessidade de realizar pesquisas mais aprofundadas no que diz respeito às contribuições da GC para a proteção do conhecimento sensível, especialmente quanto às perspectivas de desenvolvimento e inovação científica e tecnológica. 


\section{REFERÊNCIAS}

ALAVI, M., \& LEIDNER, D. E. (2001). Knowledge management and knowledge management systems: Conceptual foundations and research issues. MIS Quarterly, 107-136.

BRASIL, G. M. (2004). Formação e Inteligência Policial: desafios à Política Pública de Segurança. UFC: O público e o Privado - Revista do Programa de Pós-graduação em Sociologia da Universidade Federal do Ceará, № 4.

BUKOWITZ, W. R., \& WILLIAMS, R. L. (2002). Manual de gestão do conhecimento: ferramentas e técnicas que criam valor para a empresa. Porto Alegre: Bookman.

CAMARGO, B. V., \& JUSTO, A. M. (2013). IRAMUTEQ: um software gratuito para análise de dados textuais. Temas em psicologia, 21(2), 513-518.

CERQUEIRA, D. C., Lima, R. S. D., BUENO, S., NEME, C., FERREIRA, H., COELHO, D. \& Reis, M. (2018). Atlas da violência 2018.

Cepik, M. (2003). Espionagem e democracia. FGV Editora.

CIAI. Curso de Introdução à Atividade de Inteligência. (2015). Secretaria Nacional de Segurança Pública, 2015.

DAVENPORT, T. H., \& PRUSAK, L. (1992). Conhecimento empresarial: como as organizações gerenciam o seu capital intelectual. Rio de Janeiro: Campus, 1999.

DAVENPORT, T. H., MARCHAND, D. A., \& Dickson, T. (2004). Dominando a gestão da informação. Bookman.

Decreto $n^{o}$ 3.695, de 21 de dezembro de 2000. (2000). Cria o Subsistema de Inteligência de Segurança Pública, no âmbito do Sistema Brasileiro de Inteligência, e dá outras providências. Recuperado de: http://www.planalto.gov.br/ccivil_03/decreto/d3695.htm

Decreto de 15 de dez. de 2017. (2017). Aprova a estratégia nacional de inteligência. Recuperado de: //www.planalto.gov.br/ccivil_03/_ato2015-2018/2017/dsn/Dsn14503.htm

DETLOR, B. (2010). Information Management. International Journal of Information Management. $\mathrm{N}^{\circ}$. 30, p.103-108.

FERREIRA, V. H. R. A. (2017). Inteligência Policial e Investigação Criminal. In: HAMADA, H. H. MOREIRA, R. P. (2017). Inteligência de segurança pública contribuições doutrinárias para o cotidiano policial. Belo Horizonte: D’Plácido. 
FERRO JÚNIOR, C. M. (2008). A inteligência e a gestão da informação policial. Brasília: Fortium.

FREIRE, J. J. FURLAN, S. A. SILVEIRA, J. L. G. (2018). Gestão do conhecimento na atividade de inteligência de segurança pública - uma abordagem prática e tecnológica. Curitiba: Appris.

HAMADA, H. H. (2017). Referenciais de pesquisa em inteligência no Brasil: o olhar do pesquisador e as tendências da produção científica. In: HAMADA, H. H. MOREIRA, R. P. (2017). Inteligência de segurança pública contribuições doutrinárias para o cotidiano policial. Belo Horizonte: D’Plácido.

HENDRIKS, P. (1999). Why share knowledge? The influence of ICT on the motivation for knowledge sharing. Knowledge and Process Management, v. 6, n. 2, p. 91-100.

KENT, S. (1950). Informações estratégicas. Rio de Janeiro: Bibliex.

MARCONI, M. A. LAKATOS, E. M. (2003). Fundamentos de metodologia científica. 5. ed. - São Paulo: Atlas.

Martins, S. D. C. (2014). Gestão da Informação: estudo comparativo de modelos sob a ótica integrativa dos recursos de informação. Universidade Federal Fluminense.

MCDERMOTT, R. O'DELL, C. (2001). Overcoming cultural barriers to sharing knowledge. Journal of Knowledge Management, Bingley, v.5, n. 1, p. 76-85.

MELO, F. P. (2017). A utilização dos serviços de inteligência no inquérito policial. Curitiba: Íthala.

MELO, F. P. BITTENCOURT, J. C. BLANCHET, L. R. (2019). Técnicas de Entrevista e Interrogatório. Curitiba: Intersaberes.

MOREIRA, W. G. FERRO, A. L. (2017). Formação do profissional de inteligência no âmbito do subsistema de inteligência de segurança pública e sistema de inteligência da Polícia Militar do Distrito Federal. In: HAMADA, H. H. MOREIRA, R. P. (2017). Inteligência de segurança pública contribuições doutrinárias para o cotidiano policial. Belo Horizonte: D’Plácido.

MORGAN, G. (1996). Imagens da Organização. Trad. Cecília W. Bergamini e Roberto Coda, São Paulo: Atlas.

NONAKA, I. TAKEUCHI, H. (1997). Criação de Conhecimento na Empresa. Como as empresas Japonesas geram a dinâmica da inovação. Rio de Janeiro: Campus.

OSINSKI, M., ROMAN, D. J., \& SELIG, P. M. (2015). Compartilhamento de conhecimento: estudo bibliométrico das publicações acadêmicas realizadas de 1994 a 2014. Perspectivas em Ciência da Informação, 20(4), 149-162. 
Portaria no 42 GSIPR, 19 de agosto de 2009. (2009). Institui, no âmbito da Agência Brasileira de Inteligência - ABIN, o Programa Nacional de Proteção do Conhecimento Sensível - PNPC e dá outras providências. Recuperado de: https://www.legisweb.com.br/legislacao/?id=213674

PROBST, G.; RAUB, S.; ROMHARDT, K. (2002). Knowledge management in organization. Krakow: Publishing Office.

ROCKEMBACH, S. J. (2017). Os Desafios da Inteligência de Segurança Pública para os próximos cinco anos. In: HAMADA, H. H. MOREIRA, R. P. (2017). Inteligência de segurança pública contribuições doutrinárias para o cotidiano policial. Belo Horizonte.

SIQUEIRA, R. F. D. R. S. (2009). Contra-inteligência. In CASTRO, C. A.; RONDON FLIHO, E. B. (2009) Inteligência de Segurança Pública. Curitiba: Juruá.

TONET, H. C.; PAZ, M. G. T. (2006). Um modelo para o compartilhamento de conhecimento no trabalho. RAC-Revista de Administração Contemporânea, v. 10, n. 2, p. 75-94. 